\title{
True Colours: explorations in art, design and research
}

\author{
Malcolm Innes, Edinburgh Napier University
}

\section{Do You See What I See?}

It is always an interesting question: do you see colour the same way that I see colour? As my initial training was as an artist, it is possible that I approach colour very differently from someone with a scientific background. But do all artists or all scientists see the same, how do specialists in each discipline see colour? Does a chemist see colour differently from a physicist and do they see colour differently from a neurologist? Does a painter see colour differently from a graphic designer or an advertising art director? How much does our training contribute to our view of colour and do our professional silos prevent us from seeing the world as others do? As someone whose practice crosses art, design and strays into science, I am always intrigued to know how other people's training and professions shape the way they see the world.

\section{A colour education}

Having studied for four years at Art School, I can summarise what I was taught about colour in one word - nothing. An art education is a strange thing, in some subjects there is little in the way of education and much in the way of self-directed exploration. We were expected to discover our own path by exploring subject matter ourselves and experimenting with media. We were expected to re-invent the wheel to find our own style. A style that, in some way, would represent us and who we were. This included developing our own approach to the use of colour.

This seems far removed from a scientific training that is about learning the truths of the subject and mastering the accepted tools, techniques and methodologies. The Sciences are creative subjects, but not many people try to create their own form of chemistry because the other chemistry has been done before.

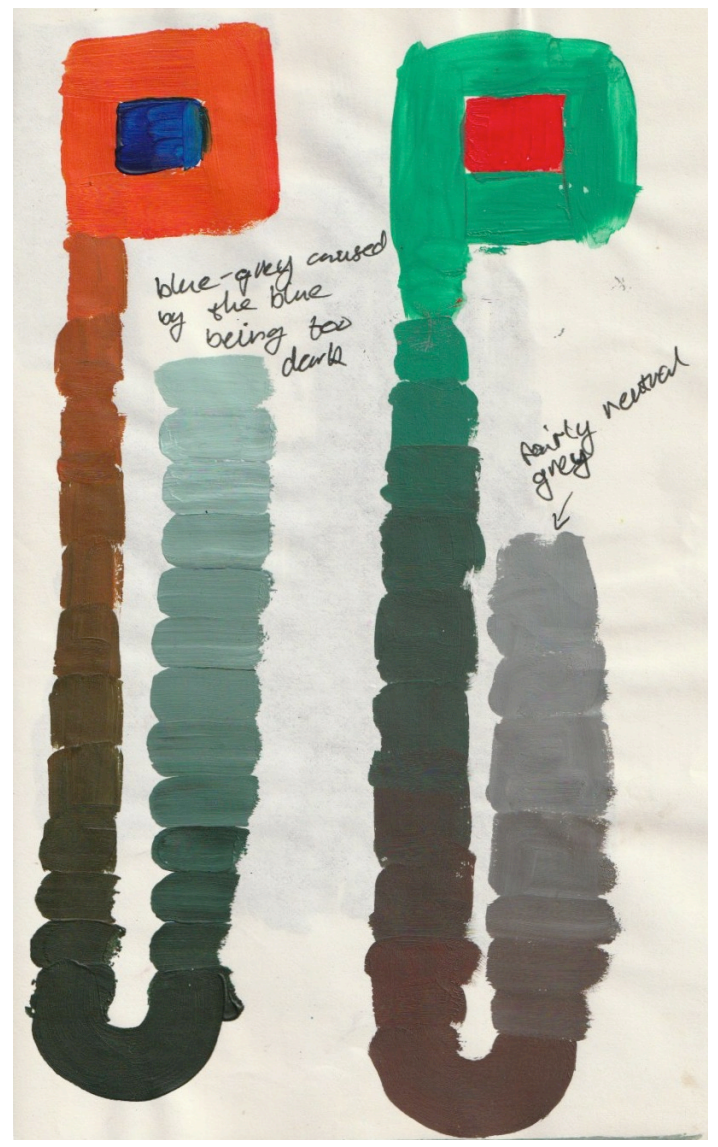

Colour greys. The author's sketchbook exploration of mixing complementary colours to create a 'colour black' and adding white to create a grey that retains subtle tints of colour. 
It should be noted that not all art education is the same. The Bauhaus School was famous for its systematic approach to art and design. This included a seminal course in colour, created by Joseph Albers. However, this course also took a very experimental approach to colour and expected the students to find their own truths about the subject, "The aim of such study is to develop - by trial and error - an eye for colour." (Albers 1963, p.1).

With hindsight, I wish that I had the opportunity to study the Bauhaus colour course; the inquisitive approach that built theory out of practice (Albers 1963, p.1) seems to fit with what has become my own approach to light and colour. Over the course of many small steps, my default position is now to question everything that I find in the way of conventional wisdom about light and colour. Perhaps I would have got there quicker if my early education had included Joseph Alber's exaltation that, "What counts here - first and last - is not so-called knowledge or so-called facts, but vision - seeing." (Albers 1963, p.2)

\section{$\underline{\text { A Language of Colour }}$}

Our sense of colour is part physiological and part psychological. Our colour sense is shaped by our past experiences and what we have learned or been taught about light, colour and materials. Your unique set of visual experiences is unlikely to be replicated in another individual. Nevertheless, to a certain degree, the unrepeatable nature of our personalised experience of colour can be mediated by language. Where we share a common language, we can agree on a common description of colour. Children are not born with a language of colour, they have to learn to relate individual visual experiences with colour names. For children this is not always an easy task to master (Deutscher 2011, p71). Language allows us to agree on verbal descriptions of colour sensations, but the limitations of words can mean that our view of colour is often restricted by the imprecision of language.

\section{Where is Brown?}

Of all the colours we have words for, brown is perhaps one of the strangest. As an artist, brown seems to be unknowable. Brown appears on the paint palette all the time when we try to mix pigments that are perhaps not as pure as we had hoped. The rules of subtractive colour mixing that we are taught at school do not prepare us for the truth that many pigment combinations actually seem to unite to make brown. Artists find it too easy to mix a brown accidentally, but they also find it difficult to mix a pleasing brown when required. For artists, brown seems very hard to know and is often actively avoided.

For a lighting designer, brown is equally challenging. In the days when colour in lighting was largely produced by filters placed in front of white light sources, the lighting designer had a huge swatch book of hundreds of coloured gels to choose from. Featuring 
bold saturated colours through to subtle tints and precise colour temperature shifts, these swatch books covered all the colours of the rainbow and even non-spectral colours like purples - but no browns. It appeared that there was no brown light in the theatre, I really didn't understand why.

"You can make a brown patch by producing a spot of orange (any orange will do, spectral or a mixture) and then surrounding it by a brighter light of any colour" (Livingstone, 2002. p. 30)

Livingston's (2002) description of brown being a particular form of orange does go some way to reveal the true nature of the colour. Yet even here, the imprecision of language hinders our understanding. Although we appreciate what is being said by Livingstone, there is an even simpler way of saying what she means - brown is dark orange. 'Dark' is a relative word, it reinforces what Livingston says, "a colour surrounded by a lighter colour", without the ambiguity of simply saying 'orange'. My immediate reaction to reading the sentence was to think, "That is wrong. That means that you could never see orange on a white background or brown on a black background. I am fairly sure I have seen orange colours printed on white paper."

The premise of Livingston's statement may be correct, but the language leaves uncertainty. This is unfortunate because, as described above, the true nature of brown often seems to be very difficult to grasp. However, if the name brown was never used and the colour was only ever described as a dark orange, I would certainly have always understood it better, and possibly appreciated the colour more. By semantically separating orange and brown, we are made to think of them as separate entities. Furthermore, the darker versions of colours tend to have descriptive names like deep blue, royal blue or dark green. Each of these phrases creates an instant mental image of that colour, inspired by our inbuilt colour memory. Saying 'dark orange' does not create a mental image in the same way because, for some reason, we use 'brown', a completely unrelated name for that colour.

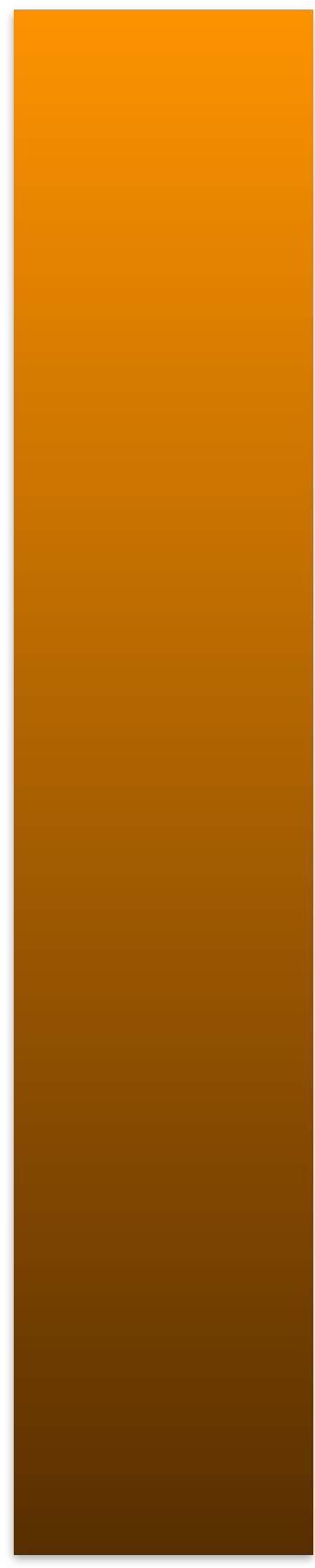

When does a dark orange colour become brown?

\section{Objective or Subjective Truth}

Once you begin to think about the colour brown, things can become even more peculiar. Brown is usually described as a non-spectral colour, but if brown can be a dark 
version of a spectral orange; surely brown must be also be a spectral colour? But, whether a spectral colour or a mixture, where does brown appear on the CIE chromaticity diagram? Actually, where are any of the dark shades on the chromaticity diagram? If the dark shades are missing, is the chromaticity diagram a slice through a three dimensional shape (yes it is)? Is that slice a horizontal cut - after all, there are no dark colours, but there are pale tints and whites? These are the kinds of questions that I am plagued by - perhaps the questioning is a hangover from my artistic training.

Whilst a scientific mind applies the scientific method to try and discover truths that explain the natural world, artists are also seeking truth. Although an artistic exploration may not be able to quantify or explain a natural phenomenon, the artist may be able to capture a description of a phenomenon or experience which can help to shine a light on the natural world. In visually signposting the parts of our universe that I find most interesting, I do often feel that this artistic description is not enough for me. For my own inquisitive nature, I need to explore why we experience the world the way that we do. Given that colour is a personal response to visible light, I am keen to explore the facts of light and colour through personal exploration. This is partly because, in many cases, the received wisdom does not seem to match my own personal experience of light and colour.

\section{Where is Colour?}

"Since we see that the quality of colour is revealed by means of light, it is to be deduced that where there is more light will be seen more of the true quality of the illuminated colour; and where there is more shadow the colour will be tinged with this shadow."

Leonardo da Vinci, quoted in Universal Leonardo. Available at: http:// www.universalleonardo.org/trail.php? trail $=543 \&$ work $=306$

In the language of psychology, 'a schema' represents a model that we hold in our mind to help describe and categorise the world around us. One of the first schemas that human infants learn is the 'body schema' which divides the world into parts that, 'are me' and parts that, 'are not me' (Hayes, 2003, p110). One of the curious things about our relationship with colour is that we tend to think of colour as being an innate feature of the materials and

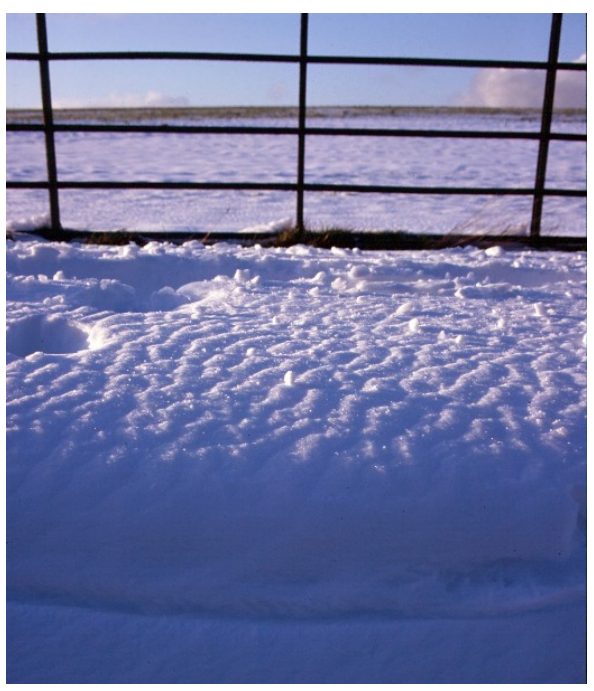

A clear blue sky tinges shadows on snow. Author's photograph. 
objects around us. We might describe 'a red chair', meaning that the colour is a characteristic of the chair itself and therefore independent of the observer. In the body schema of an infant, colour would consequently be classed as 'not me'.

Instead, we know that colour is an individual and personal perceptual response to particular wavelengths of light, colour is very human. To paraphrase James Clerk Maxwell, some people look for the truth about colour in the properties of pigments or in rays of light, but the truth is in ourselves (Livingstone 2002, p.28). Our response to colour is both physiological and psychological (Gregory 1987). Our perception of colour is also shaped by our cultural and personal past experiences of colour (Innes 2012, p.35). Taking all of these factors into account, in the body schema, colour is very much a part that, 'is me'.

\section{The Art of Colour Science}

Colour science in all its many facets (chemistry, physics, neurology...), has done a great deal to expand our understanding of light and colour and to explain many of the mysteries. However, the role of art in this quest should not be neglected.

Long before the dot screen technique of colour printing created thousands of colours from only three or four inks, artists were exploiting a keen understanding of the way that human vision works. Since our earliest ancestors, artists have always used subtractive colour mixing to combine two or more pigments to make a new colour. However, painters have also exploited tricks of additive colour

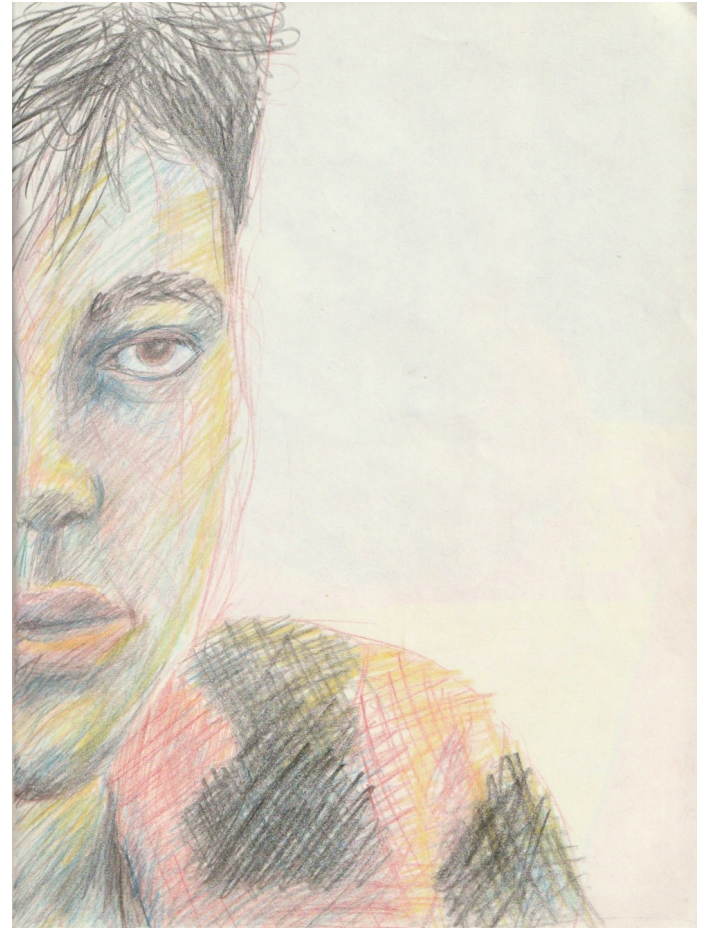

Author's drawing, coloured pencil. mixing, laying brushstrokes of dissimilar colours alongside each other such that, from a distance, a third colour is created in the mind of the viewer. This ancient technique became explicit in the works of the Pointillist painters such as George Seurat (1859-91). Seurat pushed the boundaries of 'optical fusion' in paintings that, seen close up, appear to be little more than random dabs of coloured pigment with little discernible form. Step back from the canvas and the messy dabs of paint resolve into finely crafted scenes with subtle shifts of colour and tone. Many of the colours that are apparent from a distance are virtual colours. The colour that we perceive as the viewer simply does not exist as a pigment on the canvas, it is created optically (and psychologically/physiologically) by additive colour mixing and simultaneous contrast. 
The techniques of the Pointillist painters of the late 19th Century may have been inspired by the pioneering and systematic study of colour by French Chemist Michele Eugéne Chevreul (Finlay 2014). Chevreul's ground breaking work was inspired by the artistic use of colour. Commissioned in 1820 by Les Gobelin (the Paris based Royal tapestry studio), Chevereul set out to explain many of the oddities of colour that the Royal tapestry weavers had noticed. He managed to describe why some colours seem to subtly change vibrancy or hue when seen alongside other colours, how optical mixing can occur with adjacent colours, he also described simultaneous contrast and how to adjust the edges of blocks of colour to create visually smooth graduations (Finlay 2014, p. 77). Although generations of artists had known about these idiosyncrasies of how we perceive colour and tone, it took Chevreul as a scientist to document and explain it comprehensively in his 1839 book "The Laws of Contrast of Colour" (Chevreul 1839). All of this happened 26 years before James Clerk Maxwell's publication of his "Dynamical Theory of the Electromagnetic Field" (Clerk Maxwell 1865), which finally defined light (and colour) as a small part of the electromagnetic spectrum.

Whilst Chevreul's work included a colour wheel to help identify pleasing colour combinations, his was just one of many attempts by scientists, including Isaac Newton (1704) and James Clerk Maxwell (1855), and artists including Johann Wolfgang von Goethe (1810), to codify colour. However, it was the American artist Albert Munsell (1858-1918) who, in the first decades of the 20th Century, developed what is still one of the dominant colour models. As Danny Pascale notes, "the Munsell Color System [was] the first widely accepted color order system" (Pascale 2016, p.284). One driver for Munsell to create his colour system was to create a colour notation that performed the same function as musical notation, "which had order so that one could 'hear' how a composition would sound by reading the notes." (Munsell Color 2017). This ordered notation would therefore avoid the vagaries and arbitrary nature of colour names.

\section{Your red or mine?}

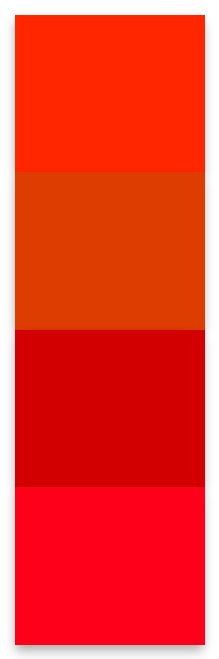

"If one says, 'red' and there are 50 people listening, it can be expected that there will be 50 reds in their minds and one can be sure that these reds will be very different."

Josef Albers (Albers 1963, p.3)

For humans, one limitation of our colour memory is defined by the constraints of our spoken language. 'Red' is a very imprecise term when describing a colour sensation and is therefore open to interpretation.

'Crimson' may be used to describe a subset of Red colours and, although this might add some precision to our colour language, there are still many variations within the range that we may call Crimson. We are also very vague 
about where the boundaries lie between named colours. Who can say when Crimson becomes Magenta?

With distance measurements, we are very used to using both precise terms and vague terms. One metre is an international standard for length and is defined precisely as the distance that light travels in a vacuum in one 299,792,458ths of a second. By comparison, 'one car length' is a very vague term. It could mean anything from $2.5 \mathrm{~m}$ for a two seat Smart Car to twice that length for a Volvo Estate. We understand that, 'a car's length' generally means some kind of average of the wide range of lengths available. With colour, we can also be vague by describing a colour as 'red', or precise, by saying 650nm red light. However, most colours we see are not pure spectral colours, meaning that a wavelength measurement is not enough. Therefore, we have colour systems that may define three dimensional qualities such as hue, saturation and value (or HSL, or CIELAB, or CIECAM, or RGB, or...). Nevertheless, whilst the metre is describing an objective physical property of length or distance, our colour appearance models are describing a psychophysical measurement. These models are a reflection of the subjective perceptual responses that an average viewer (whoever that is) has to a physical stimuli. Because these modern colour models are derived from an average of the cone spectral sensitivities of a number of people (Stockman, online), it is possible that they do not accurately model the way that any one individual, like you or I, will see colour.

\section{Models and Limitations}

Another feature of our colour models is that they cannot always differentiate between two different spectral power distributions (SPD) if they produce the same perceptual response in the (average) viewer.

For an artist, this is not an issue. If two stimuli with different SPD's produce the same response in the viewer, then in human perceptual terms, they are the same colour. For a lighting designer, the same situation could cause a problem. Metameric matches of two colour samples are only likely to exist in certain lighting conditions. As a lighting designer, I know that the colour we see in object is directly related to the wavelengths of light that I choose to illuminate the object with. A metemeric match between two colours can therefore be deliberately or inadvertently broken if the lighting conditions are changed. Whilst we seem to have a bewildering array of colour models, it is still difficult to quantify the human experience of the very variable interactions of pigment and light.

My confusion as an artist over the plethora of colour models is also reflected in my lighting designer persona where I have developed a deep scepticism of lighting metrics. The more time I have spent designing with light, the less faith I have in the quantification methods that the lighting industry relies upon. Although the attempts to create standardised metrics were very admirable and do have some value, I have now come to the conclusion 
that Lux and Lumens are far enough removed from the human visual experience of light, that we might as well be specifying light and colour by weight and waviness.

Even if the Lumen did once accurately reflect my vision, as I get older, does the Lumen still represent the spectral sensitivity of my visual response? Why is lighting design practice legislated by lighting standards and codes that mandate illuminance levels as a proxy to indicate that a space is well lit? Illuminance is not a measure of how much light we, the users of the space, will see, but simply of how much light is directed onto a surface.

Whether a surface is black, blue or white, is irrelevant for an illuminance measurement in a space, but it is critical in determining how much light is reflected towards our eyes.

Despite their ubiquity, Lux measurements alone tell us very little about how a lit space may appear to an observer. An alternative, human centric approach is beginning to gain some traction in the lighting world through the work of Kit Cuttle and his attempts to quantify the 'perceived adequacy of ambient illumination' and build a metric of 'mean room surface exitance' (Cuttle 2010; Cuttle 2015, p.30).

The difficulty of defining and modelling colour is the difficulty of defining the mechanism that perceives the colour - the human mind. The fact is that, not only are we still at the scientific infancy of understanding how the mind works, it is clear that not all minds work the same. Furthermore, in areas of human experience such as colour, we seem to manage to muddle through despite the disparity of our personal experiences. As Joseph Albers famously noted in Interactions of Colour,

"If one is not able to distinguish the difference between a higher tone and a lower tone, one probably should not make music. If a parallel conclusion were to be applied to colour, almost everyone would prove incompetent for its proper use. Very few are able to distinguish higher and lower light intensity (usually called higher and lower value) between different hues. This is true despite our daily reading of numerous black-andwhite pictures." (Albers 1963, p.12)

\section{Do I see what you see?}

So, do I see colour the same way that you see colour? As a sometime artist, sometime designer, sometime educator and sometime researcher, I don't think that I always see colour the same way as myself. Indeed, if colour preference is anything like music or food preferences, I am likely to crave different colours at different times and in different contexts. Colour is personal and is filtered by unique components of individual experience and preference, but the complex and contradictory nature of the meaning of colour in different contexts suggests that our individual experiences of colour also have temporal, geographical and linguistic influences. Despite all our attempts to define, codify and quantify the dimensions of colour, for the artist in me, colour perception is about a time and a place. Ultimately, artist or scientist, our experience of colour is 'of me'. 


\section{References:}

Albers, J. 1963, Interactions of Colour. New Haven: Yale University Press

Chevreul M. E. 1839. The Laws of Contrast of Colour

Clerk Maxwell J. 1865. A Dynamical Theory of the Electromagnetic Field. Philosophical Transactions of the Royal Society of London, Vol. 155 (1865), pp. 459-512 Available at: http://www.jstor.org/stable/108892

Cuttle, C. 2009. In the Eye of The Beholder, Society of Light and Lighting Newsletter. Vol 2 (Nov/Dec) pp. 6-8

Cuttle, C. 2015. Lighting Design: A Perception Based Approach. London: Routledge

Deutscher, G. 2011. Through the Language Glass: Why the World Looks Different in Other Languages. London: Arrow

Finlay V. 2014. The Brilliant History of Colour in Art. Los Angeles: Getty Publications

Gregory, R. L. 1987. Eye and Brain: The Psychology of Seeing. Oxford: Oxford University Press

Hayes, N. 2003. Psychology. London: Hodder.

Innes, M. 2012. Lighting for Interior Design. London: Laurence King

Livingstone, M. 2002. Vision and Art: The Biology of Seeing. New York: Abrams

Munsell Color Company, 2017. Development of the Munsell Color Order System. Available online at: http://munsell.com/about-munsell-color/development-of-the-munsellcolor-order-system/

Stockman, A. CVRL: Colour Matching Functions. Colour \& Vision Laboratory, UCL. Available online at: http://www.cvrl.org. Accessed 10/07/2017 